\title{
Pengaruh Secondary Skin Fasad Bangunan terhadap Kualitas Pencahayaan Alami Ruang Kerja
}

\author{
Erwin Yuniar Rahadian', Windi Dwiastuti' ${ }^{1}$, Nanda Annisa Maretia ${ }^{1}$, Beri Fitrian ${ }^{1}$ \\ ${ }^{1}$ Program Studi Arsitektur, Fakultas Arsitektur dan Desain \\ Itenas, Institut Teknologi Nasional Bandung \\ Email: ears@itenas.ac.id
}

\begin{abstract}
ABSTRAK
Pencahayaan merupakan suatu unsur yang sangat penting dalam perancangan suatu ruang. Kantor sebagai area kerja membutuhkan rata-rata kuat penerangan untuk kenyamanan visual sesuai SNI sebesar 350 lux, sehingga dapat menunjang pengguna beraktivitas dan memiliki produktivitas kerja yang baik. Gedung Rektorat Unpad Jatinangor merupakan bangunan yang terdiri dari empat lantai dengan fungsi utama sebagai gedung administrasi dalam bidang akademik untuk menunjang kegiatan kemahasiswaan. Gedung ini memiliki bentuk massa lingkaran dan menggunakan secondary skin pada fasad yang selain berfungsi dalam unsur estika bangunan, juga untuk mereduksi paparan radiasi panas matahari yang masuk ke dalam bangunan. Maksud dari penelitian ini adalah untuk mengetahui kualitas pencahayaan alami yang dipengaruhi oleh penggunaan secondary skin. Metode penelitian yang digunakan yaitu metode pengukuran langsung menggunakan Luxmeter dan metode pengukuran dengan simulasi software Ecotect. Hasil pengukuran langsung mengunakan Luxmeter menunjukkan kuat penerangan alami yang menghadap secondary skin lebih terang dibandingkan yang menghadap koridor sedangkan hasil pengukuran dengan simulasi software Ecotect menunjukkan kuat penerangan alami yang tidak menggunakan secondary skin lebih baik dibandingkan dengan yang menggunakan secondary skin. Sehingga penerapan secondary skin pada fasad bangunan tidak hanya untuk memenuhi unsur estetika dan perlindungan faktor iklim eksternal terhadap bangunan, namun harus juga memperhatikan perolehan pencahayaan alami yang terjadi pada ruang dalam bangunan.
\end{abstract}

Kata kunci: fasad, pencahayaan alami, ruang kerja, secondary skin.

\begin{abstract}
Lighting is a very important element in designing a space. The office as a work area requires an average lighting strength for visual comfort according to SNI of 350 lux so that it can support users' activities and have good work productivity. Unpad Jatinangor Rector Building is a building consisting of four floors with the main function as an administrative building in the academic field to support student activities. This building has a circular mass shape and uses a secondary skin on the facade which in addition to functioning in the aesthetic elements of the building, also reduces exposure to solar heat radiation that enters the building. The purpose of this study is to determine the quality of natural lighting which is influenced by the use of secondary skin. The research method used is the direct measurement method using the Luxmeter and the measurement method using the Ecotect simulation software. The direct measurement results using the Luxmeter show that the natural light strength facing the secondary skin is brighter than the one facing the corridor, while the measurement results using the Ecotect simulation software show that the natural light strength that does not use the secondary skin is better than those using the secondary skin. So that the application of secondary skin on the building facade is not only to fulfill the aesthetic element and protection of external climatic factors for the building but must also pay attention to the acquisition of natural lighting that occurs in the space in the building.
\end{abstract}

Keywords: facade, natural lighting, office room, secondary skin. 


\section{PENDAHULUAN}

Kantor sebagai area kerja membutuhkan tingkat kenyamanan visual dengan pencahayaan alami yang memadai agar pengguna di dalamnya dapat melakukan aktivitas dengan lancar dan memiliki produktivitas kerja yang baik. Kenyamanan visual dapat tercapai jika syarat-syaratnya teraplikasikan secara optimal antara lain melalui kesesuaian rancangan dengan standar pencahayaan yang direkomendasikan dan penataan layout ruangan yang sesuai dengan distribusi pencahayaan.

Pencahayaan alami (day lighting) adalah penggunaan cahaya yang bersumber dari alam sebagai penerangan yang berasal dari matahari [1]. Masalah yang kemudian muncul adalah tentang kenyamanan visual yang diperoleh dari pencahayaan alami dalam ruang. Menurut Boyce (2013), tersedianya pencahayaan alami secara optimal sangat diinginkan karena memenuhi dua kebutuhan dasar manusia, yaitu kebutuhan visual untuk melihat baik bidang kerja maupun ruangan dan untuk mengalami simulasi lingkungan dari efek pencahayaan tersebut [2].

Gedung Rektorat Unpad ini berada di dalam kompleks Unpad yang terletak di Jalan Raya Jatinangor KM-21, Bandung. Menurut arsitek dari gedung tersebut, penggunaan bentuk lingkaran memungkinkan fasad yang seragam pada semua sisi, sehingga tidak ada sisi belakang pada bangunan. Fasad bangunan Gedung Rektorat Unpad menggunakan secondary skin dengan material GRC motif Kujang, seperti terlihat pada Gambar 1.

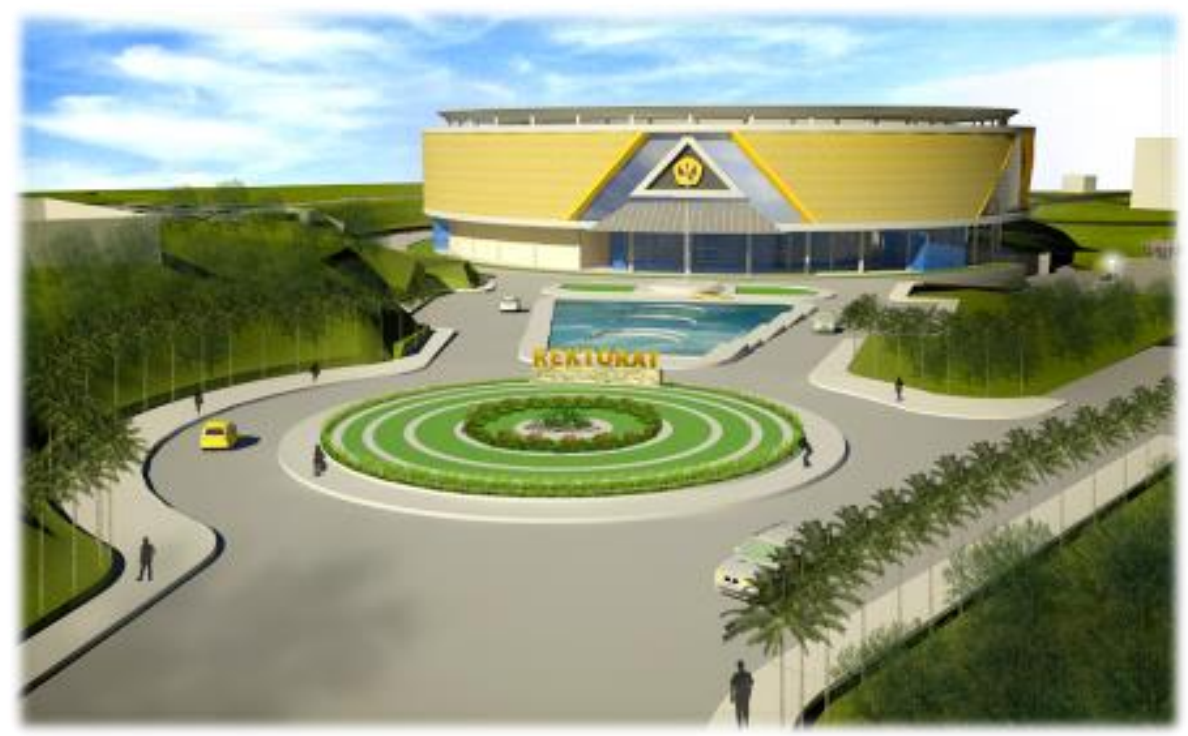

Gambar 1. Gedung Rektorat Unpad

Sumber : Dokumen Konsep Konsultan PT. Architeam, 2016

Knaack (2007), menyatakan bahwa secondary skin atau double skin pada bangunan selain berperan dalam meningkatkan nilai estetika fasad bangunan, juga berperan dalam mereduksi paparan radiasi panas matahari yang menerpa bangunan, mereduksi angin, mereduksi kebisingan dari luar ke ruang dalam, dan mereduksi cahaya yang diterima bangunan, dimana cahaya yang diterima oleh pengguna bangunan adalah cahaya tidak langsung [3]. Dengan latar belakang dan rancangan bangunan Gedung Rektorat UNPAD tersebut, maka penelitian ini bertujuan untuk mengetahui kenyamanan visual pada ruang dalam kantor yang dipengaruhi oleh adanya secondary skin pada fasad bangunan. 


\section{METODOLOGI}

Metode penelitian yang digunakan adalah metode deskriptif baik kualitatif maupun kuantitatif. Metode kuantitatif meliputi pengukuran langsung dengan menggunakan alat bantu Luxmeter berdasarkan penentuan luas ruangan, orientasi ruang, dan luas bukaan. Selain itu, pengukuran juga dilakukan menggunakan simulasi software Ecotect dengan model Bangunan Rektorat Unpad baik yang menggunakan secondary skin maupun tanpa secondary skin. Metode kualitatif meliputi pengukuran berdasarkan kuesioner respon pengguna bangunan terhadap kenyamanan visual saat bekerja.

\subsection{Fasad Bangunan}

Sandak (2019) mendefinisikan bahwa dalam arsitektur, fasad adalah pembatas antara ruang luar dengan ruang dalam bangunan. Fasad berperan dalam menjaga konsistensi iklim mikro dalam bangunan terhadap pengaruh lingkungan eksternal bangunan, khususnya terkait dengan kondisi iklim dimana bangunan berada [4]. Pembatas ini dapat berupa konstruksi load-bearing yang terdiri dari monolithic bearing wall seperti dinding bata, batu, dan beton, load-bearning cavity walls seperti dinding berongga dan konstruksi rangka ringan, serta konstruksi non-load-bearing yang terdiri dari konstruksi frame and infill seperti bukaan dan jendela, sistem cladding, dan curtain wall [5].

Double skin façade atau secondary skin merupakan salah satu bentuk pada fasad berupa suatu lapisan tambahan sebagai kulit di sisi luar bangunan, yang bertujuan untuk meningkatkan aspek estetika dan performa bangunan terhadap faktor eksternal seperti kondisi iklim. Jika dirancang dengan benar, maka dapat memberikan peningkatan performa iklim mikro dalam bangunan yang terkait dengan penggunaan energi, dibandingkan dengan fasad single skin (tunggal) [6].

Penerapan secondary skin pada fasad bangunan dengan memperhatikan kriteria motif/ pola, jarak, material, tipe, dan teknologi, dapat menurunkan tingkat silau pada ruang dalam bangunan [7]. Namun penurunan tingkat silau pada ruang dalam bangunan harus tetap memenuhi persyaratan minimum pencahayaan yang dibutuhkan pada ruang tersebut.

\subsection{Pencahayaan Alami}

Pencahayaan alami siang hari adalah upaya mendapatkan pencahayaan di dalam bangunan pada siang hari, yang bersumber dari pencahayaan alami yaitu matahari. Soegijanto (1999) menjelaskan bahwa yang dimaksud cahaya alami (siang hari) adalah cahaya matahari langsung yang disebut cahaya matahari, dan cahaya matahari difus yang disebut cahaya langit [8]. Pada umumnya cahaya matahari dibagi menjadi tiga [9], yaitu Sunlight, cahaya matahari langsung dan tingkat cahayanya tinggi; Daylight, cahaya matahari yang sudah tersebar di langit dan tingkat cahayanya rendah; dan Reflected light, cahaya matahari yang sudah dipantulkan.

\subsection{Metode Pengukuran Menggunakan Luxmeter}

Luxmeter adalah alat ukur kuat penerangan dalam suatu ruang. Satuan ukuran Luxmeter adalah lux [9]. Untuk mengetahui kuat penerangan pada pencahayaan alami siang hari, perlu diketahui faktor-faktor yang menentukan besar kuat penerangan yang terukur di suatu titik ukur, istilah-istilah dalam pengukuran, dan jenis titik ukur.

Terdapat beberapa penentu kuat penerangan yang terukur pada bidang kerja [10], yaitu sebagai berikut: A. Hubungan geometris antara titik ukut dan lubang cahaya.

Terdapat sistem pencarian lubang cahaya efektif (LCE) dan titik ukur ke arah lubang cahaya. Posisi titik ukur adalah $1 / 3 \mathrm{~d}$ dari bidang lubang cahaya (BLC). $\mathrm{d}$ adalah jarak antara BLC dengan permukaan dalam dinding yang berhadapan.

B. Ukuran dan posisi lubang cahaya

Dimensi dan posisi lubang cahaya akan menentukan besar kuat penerangan yang terukur di titik ukur.

C. Distribusi terang langit 
Kondisi langit terkait distribusi awan dan cuaca akan menentukan besar kuat penerangan yang terukur di titik ukur.

D. Bagian langit yang dapat diukur dari titik ukur

Biasanya terdapat penghalang, sehingga tidak semua langit terlihat dari titik ukur. Artinya, tidak semua cahaya langit diterima oleh titik ukur tersebut

E. Tingkat transparasi lubang cahaya

Makin transparan lubang cahaya, makin besar kuat penerangan yang terukur di titik ukur [1].
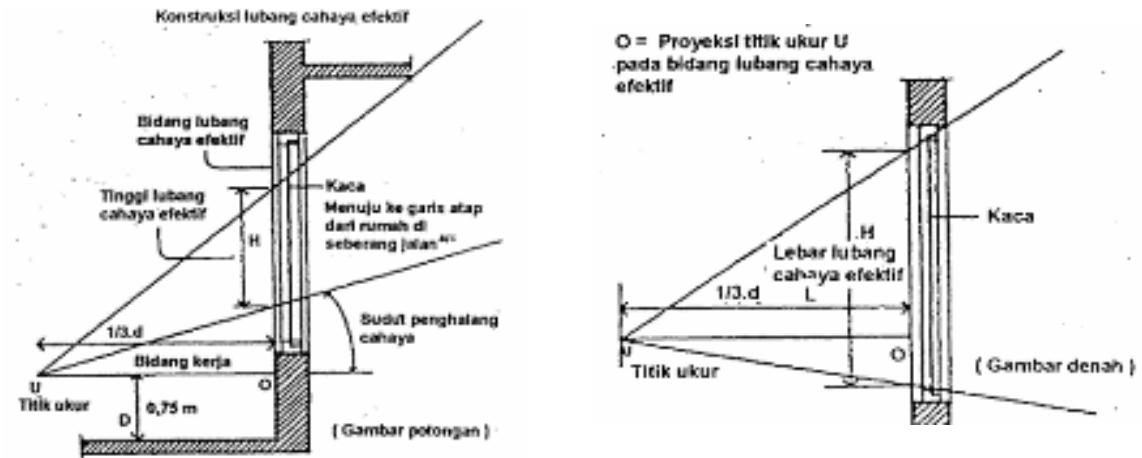

Gambar 2. Potongan Bidang Kerja, Lubang Cahaya dan Titik Ukur Sumber : SNI 03-2396-2001 Tata Cara Perancangan Sistem Pencahayaan Alami pada Bangunan Gedung [10]

Ketiga titik ukur tersebut mewakili seluruh titik pengukuran kuat penerangan pada bidang kerja. Jika kuat penerangan pada bidang kerja yang terukur di salah satu titik ukur ruang belum memenuhi syarat minimal kenyamanan visual, penerangan alami di ruang tersebut harus dibantu pencahayaan buatan. Agar hasil pengukuran akurat dan valid, terdapat kriteria jumlah TUU ke arah panjang ruang. Jika panjang ruang lebih dari $7 \mathrm{~m}$, TUU harus ditambah agar jarak antara titik ukur tidak lebih dari $3 \mathrm{~m}$ [9].

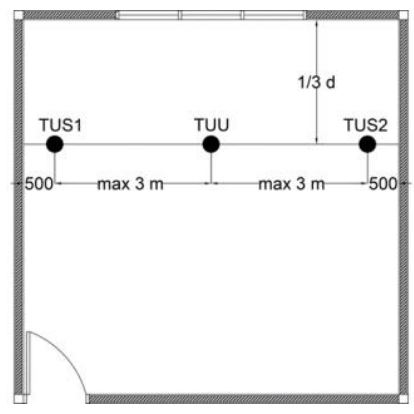

Gambar 3. Gambar 2. Posisi Titik Ukur pada Bidang Kerja Sumber : Fisika Bangunan 2, (Latifah, 2015) diolah

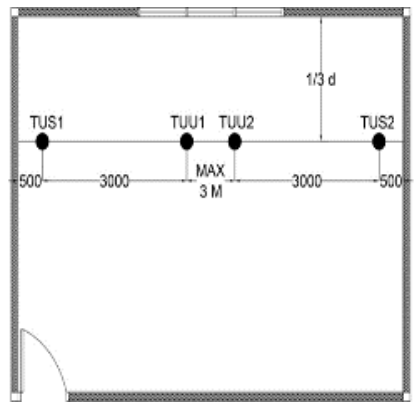

Gambar 4. Pengukuran Ruang dengan Panjang Lebih dari 7 m Sumber : Fisika Bangunan 2, (Latifah, 2015) diolah 


\subsection{Standar Pencahayaan}

Pemanfaatan pencahayaan alami pada ruang dalam harus memenuhi standar minimum sesuai aktifitas dan memenuhi kenyamanan visual. Semakin tinggi kebutuhan konsentrasi kerja visual, akan membutuhkan kuat penerangan yang makin besar. Sebab jika kuat penerangannya kurang maka pengguna akan merasa kurang nyaman secara visual dan akan cepat lelah [9]. Soegijanto (1999) menjelaskan, kuat penerangan dapat mengakibatkan terjadinya penyilauan. Penyilauan adalah kondisi dimana terjadi kondisi ketidaknyamanan atau pengurangan dalam kemampuan melihat suatu objek, yang disebabkan oleh luminasi objek yang terlalu besar, distribusi luminasi yang tidak merata, atau kontras yang berlebihan [8].

\subsubsection{Standar Pencahayaan Ruang Kerja}

Standar pencahayaan untuk ruang kerja adalah 350 lux, untuk ruang direktur/ ruang rektor adalah 350 lux sedangkan untuk ruang arsip 300 lux, lihat Tabel 1.

Tabel 1. Standar Pencahayaan

\begin{tabular}{ll}
\multicolumn{1}{c}{ Fungsi Bangunan } & Kuat Penerangan (lux) \\
\hline R. Kerja & 350 lux \\
\hline R. Direktur/ R. Rektor & 350 lux \\
\hline R. Rapat & 300 lux \\
\hline R. Arsip & 150 lux \\
\hline R. Komputer & 350 lux \\
\hline Sumber : SNI 03-6197-2011 Konservasi Energi pada Sistem Pencahayaan [11], diolah
\end{tabular}

\subsubsection{Kuat Penerangan Minimum yang Diperlukan Berdasarkan Aktivitas}

Berdasarkan Tabel 2 kuat penerangan untuk aktivitas orang membaca, menulis, dan pengaturan arsip adalah 350 lux.

Tabel 2. Kuat Penerangan Minimum yang Diperlukan Berdasarkan Aktifitas

\begin{tabular}{llc}
\hline No & \multicolumn{1}{c}{ Aktivitas } & $\begin{array}{c}\text { Kebutuhan Kuat } \\
\text { Penerangan }\end{array}$ \\
\hline 1 & Berjalan di kantor, agar bisa membedakan barang-barang & 20 Lux \\
\hline 2 & $\begin{array}{l}\text { Memeriksa serta menghitung stok barang secara kasar, } \\
\text { merakit barang-barang besar }\end{array}$ & 100 Lux \\
\hline 3 & Membaca, menulis, dan pengaturan arsip di kantor & 350 Lux \\
\hline 4 & Memeriksa daftar angka dan merakit barang-barang kecil & 700 Lux \\
\hline
\end{tabular}

\subsubsection{Standar Kebutuhan Penerangan}

Berdasarkan Tabel 3 kebutuhan penerangan untuk kerja kantor masuk ke dalam kategori kerja umum dan detail wajar dengan kuat penerangan 400 lux dan indeks kesilauan 25. Menurut Thojib (2013), kenyamanan visual dalam ruang dapat dicapai dengan memodifikasi interior dan eksterior bangunan. Modifikasi eksterior melalui penambahan shading device, memperbesar jendela, atau menambahkan skylight [13].

Tabel 3. Kebutuhan Penerangan

\begin{tabular}{llcc}
\hline No. & Kerja Visual & $\begin{array}{c}\text { Kuat } \\
\text { Penerangan } \\
(\text { Lux })\end{array}$ & $\begin{array}{c}\text { Indeks } \\
\text { Kesilauan }\end{array}$ \\
\hline 1. & Penglihatan biasa & 100 & 28 \\
\hline 2. & Kerja kasar dengan detail besar & 200 & $25-28$ \\
\hline 3. & Kerja umum dengan detail wajar & 400 & 25 \\
\hline
\end{tabular}




\begin{tabular}{llcc}
\hline No. & \multicolumn{1}{c}{ Kerja Visual } & $\begin{array}{c}\text { Kuat } \\
\text { Penerangan } \\
(\text { Lux })\end{array}$ & $\begin{array}{c}\text { Indeks } \\
\text { Kesilauan }\end{array}$ \\
\hline 4. & $\begin{array}{l}\text { Kerja lumayan keras dengan detail kecil (studio } \\
\text { gambar, menjahit) }\end{array}$ & 600 & $19-22$ \\
\hline 5. & $\begin{array}{l}\text { Kerja keras, lama, detail kecil (perakitan barang halus, } \\
\text { menjahit dengan tangan) }\end{array}$ & 900 & $16-22$ \\
\hline 6. & $\begin{array}{l}\text { Kerja sangat keras, lama, detail sangat kecil (pemotongan } \\
\text { batu mulia, tisik halus, mengukur benda-benda sangat kecil) }\end{array}$ & $1.300-2.000$ & $13-16$ \\
\hline $7 . \quad \begin{array}{l}\text { Kerja luar biasa keras dengan detail sangat kecil (arloji, dan } \\
\text { pembuatan instrumen) }\end{array}$ & $2.000-3.000$ & 10 \\
\hline Sumber : The Lighting Handbook, Dilura (2011) [12], diolah & &
\end{tabular}

\section{HASIL DAN PEMBAHASAN}

\subsection{Hasil Pengukuran Pencahayaan Alami Menggunakan Luxmeter}

Hasil dari pengukuran ini, disimpulkan dengan mengambil beberapa sampel ruangan berdasarkan arah mata angin. Pengukuran mengacu pada SNI 03-2396-2001 tentang Tata Cara Perancangan Sistem Pencahayaan Alami pada Bangunan Gedung.

\subsubsection{Ruang Rumah Tangga (Timur)}

Ruang Rumah Tangga yang menghadap ke secondary skin, posisi ruang lihat Tabel 4 yang diberi tanda merah, pada jam 09.05 memperoleh kuat penerangan dengan kisaran 88-658 lux sedangkan yang menghadap koridor pada jam 09.05 memperoleh kuat penerangan dengan kisaran 0-182 lux. Bukaan yang menghadap ke secondary skin intensitas cahayanya lebih terang dibandingkan yang menghadap koridor, sedangkan kuat penerangan pada Ruang Rumah Tangga yang menghadap secondary skin pada jam 09.05 adalah rata-ratanya tidak kurang dari 350 lux. Hasil analisis kuat penerangan berupa spektrum warna dapat dilihat pada Tabel 4.

Tabel 4. Hasil Pengukuran Kuat Penerangan Alami Ruang Rumah Tangga di Lantai 2

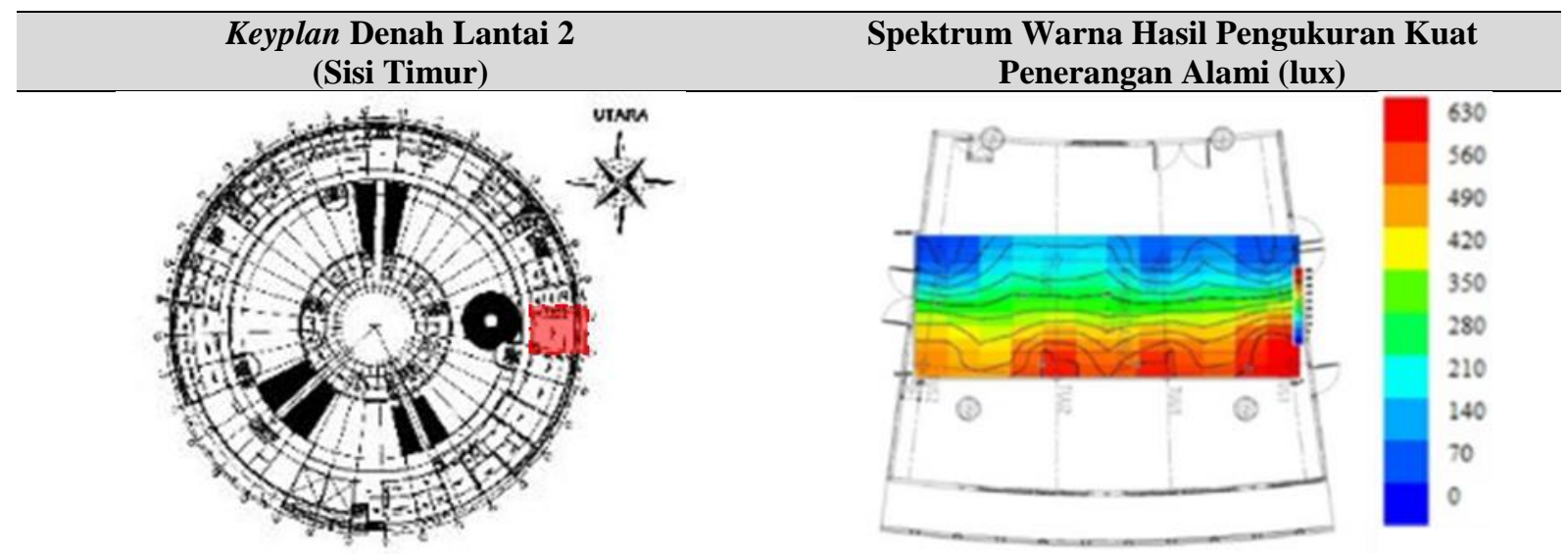

Sumber : Data PT. Architeam, (2016) dan hasil analisis

\subsubsection{Ruang Hukum dan Tata Laksana (Barat)}

Ruang Hukum dan Tata Laksana yang menghadap ke secondary skin pada jam 10.19 memperoleh kuat penerangan berkisar antara 500-1250 lux sedangkan yang menghadap ke koridor pada jam 10.19 memperoleh kuat penerangan berkisar 80-130 lux. Bukaan yang menghadap ke secondary skin intensitas cahayanya lebih terang dibandingkan yang menghadap koridor. Kuat penerangan Ruang Hukum dan 
Tata Laksana pada jam 10.19 yang menghadap secondary skin rata-ratanya tidak kurang dari 350 lux. Hasil analisis kuat penerangan berupa spektrum warna dapat dilihat pada Tabel 5.

Tabel 5. Hasil Pengukuran Kuat Penerangan Alami Ruang Hukum dan Tata Laksana di Lantai 3

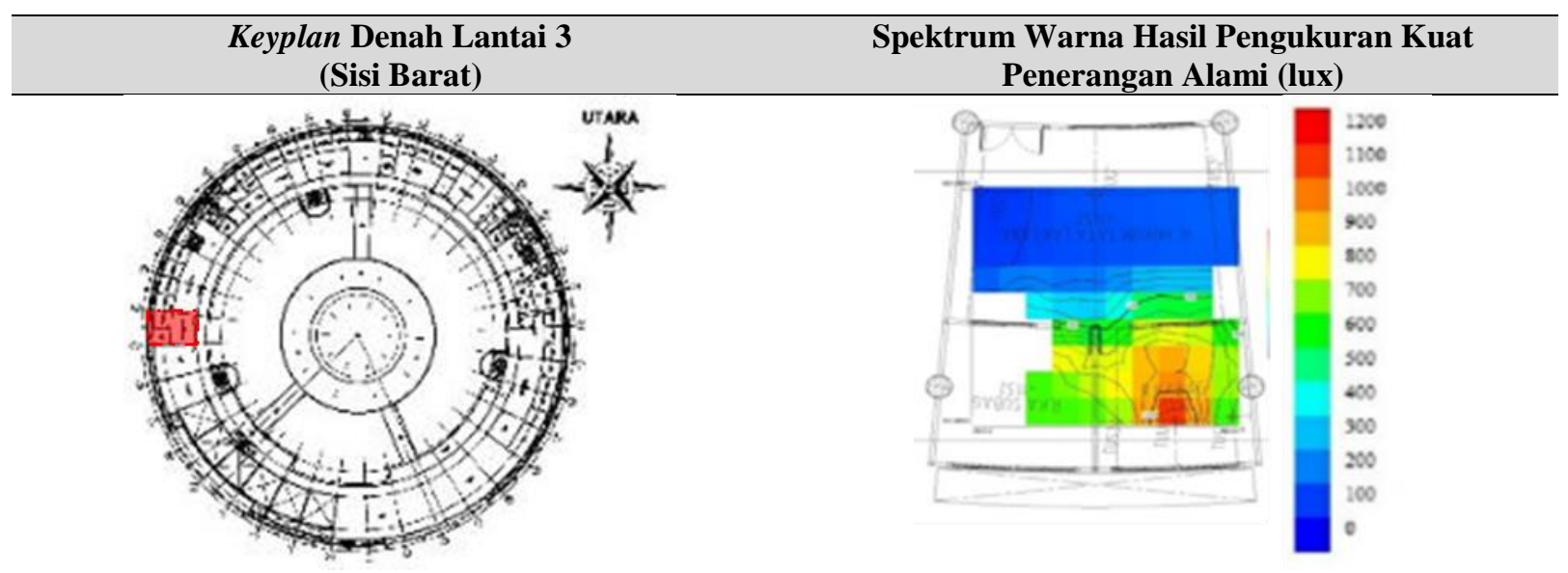

Sumber: Data PT. Architeam (2016) dan hasil analisis

\subsubsection{Ruang Kepegawaian (Utara)}

Ruang Kepegawaian yang menghadap ke secondary skin pada jam 09.11 memperoleh kuat penerangan berkisar antara 150-270 lux sedangkan yang menghadap ke koridor pada jam 09.11 memperoleh kuat penerangan berkisar 60-210 lux. Bukaan yang menghadap ke secondary skin intensitas cahayanya lebih terang dibandingkan yang menghadap koridor. Kuat penerangan pada Ruang Kepegawaian masih di bawah standar minimum SNI yang batasnya 350 lux. Hasil analisis kuat penerangan berupa spektrum warna dapat dilihat pada Tabel 6.

Tabel 6. Hasil Pengukuran Kuat Penerangan Alami Ruang Kepegawaian di Lantai 2

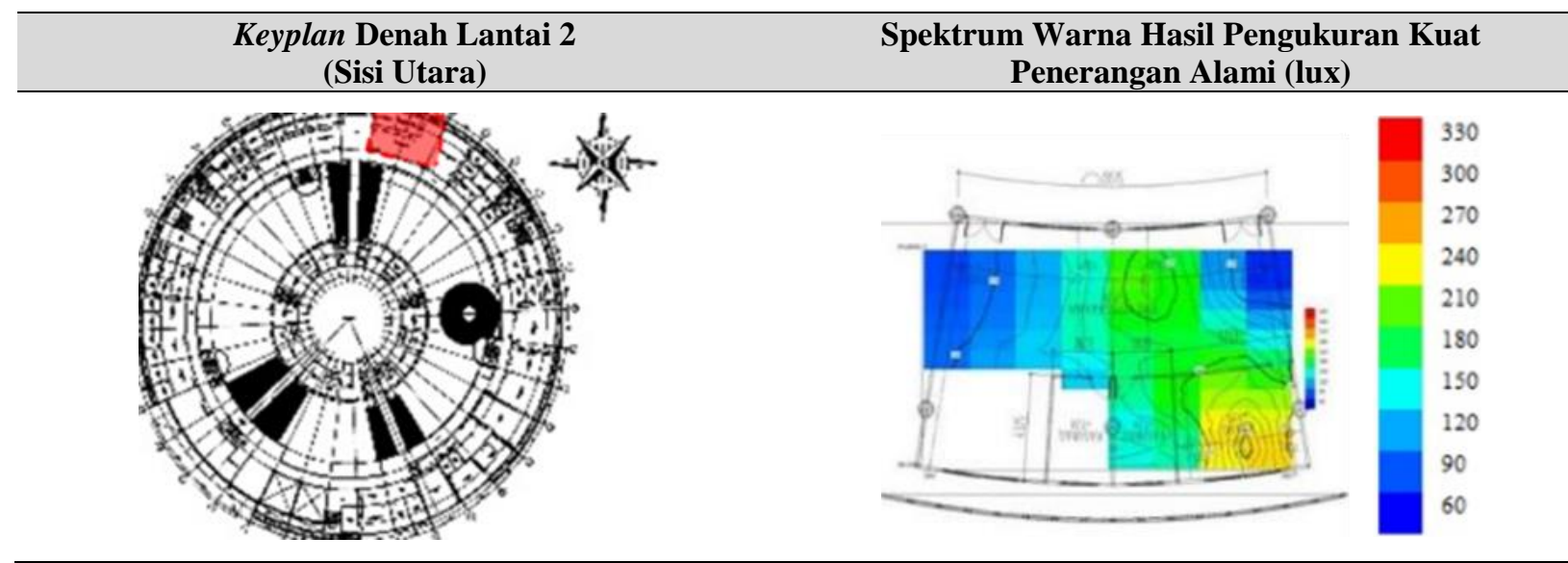

Sumber : Data PT. Architeam (2016) dan hasil analisis

\subsubsection{Ruang VVIP (Selatan)}

Ruang VVIP yang menghadap ke secondary skin pada jam 09.41 memperoleh kuat penerangan berkisar antara 140-300 lux sedangkan yang menghadap ke koridor pada jam 09.41 memperoleh kuat penerangan berkisar 30-120 lux. Bukaan yang menghadap ke secondary skin intensitas cahayanya lebih terang dibandingkan yang menghadap koridor. Kuat penerangan pada Ruang VVIP yang menghadap secondary skin pada jam 09.41 rata-ratanya masih di bawah standar minimum SNI yang batasnya 350 lux. Hasil analisis kuat penerangan berupa spektrum warna dapat dilihat pada Tabel 7. 
Tabel 7. Hasil Pengukuran Kuat Penerangan Alami Ruang VVIP di Lantai 2

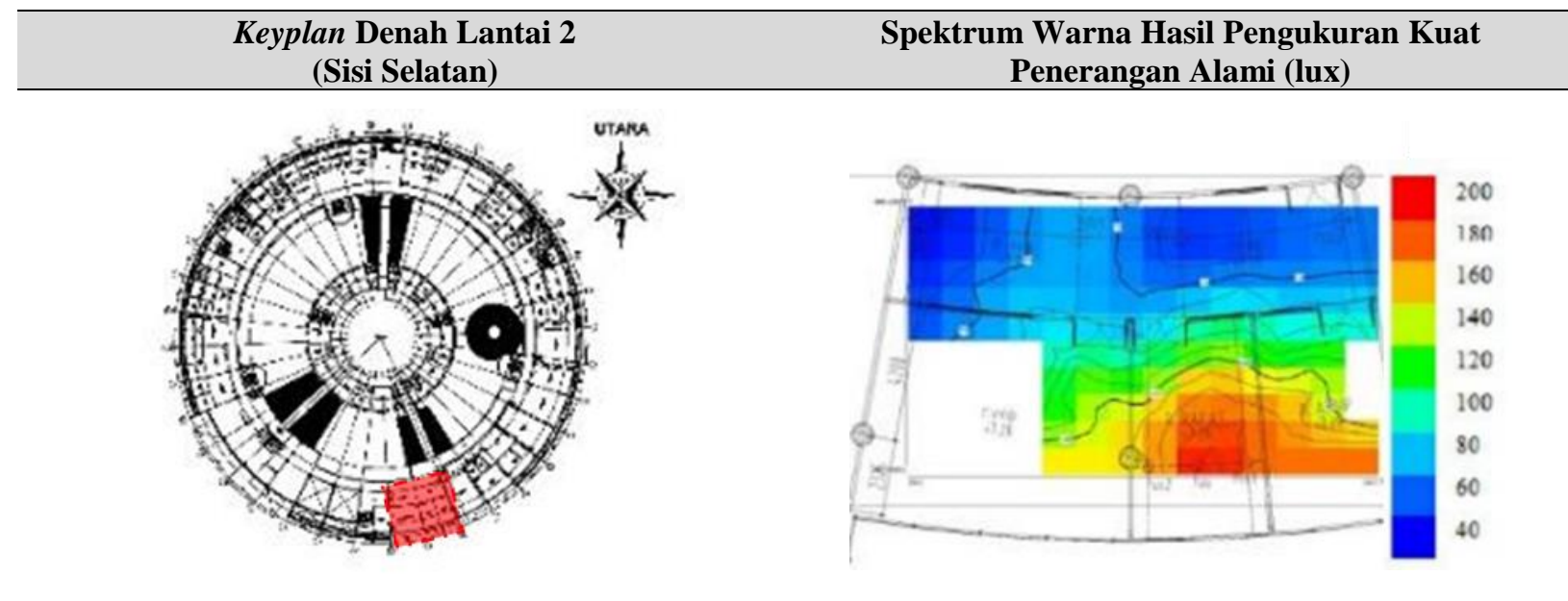

Sumber : Data PT. Architeam (2016) dan hasil analisis

\subsection{Hasil Pengukuran Penerangan Alami Menggunakan Simulasi Ecotect \\ 3.2.1 Ruang Rumah Tangga (Timur)}

Simulasi pengukuran pada Ruang Rumah Tangga yang menggunakan secondary skin pada jam 09.00 memperoleh kuat penerangan berkisar 447.56 lux. Ruang Rumah Tangga tanpa secondary skin pada jam 09.00 memperoleh kuat penerangan berkisar 540.79 lux, kuat penerangan ini terlalu besar jauh melebihi 350 lux sehingga menimbulkan silau. Hasil simulasi kuat penerangan alami berupa spektrum warna, menggunakan software Ecotect dapat dilihat pada Tabel 8.

Tabel 8. Perbandingan Kuat Penerangan Alami antara Menggunakan Secondary Skin dan Tanpa Menggunakan Secondary Skin, pada Ruang Rumah Tangga

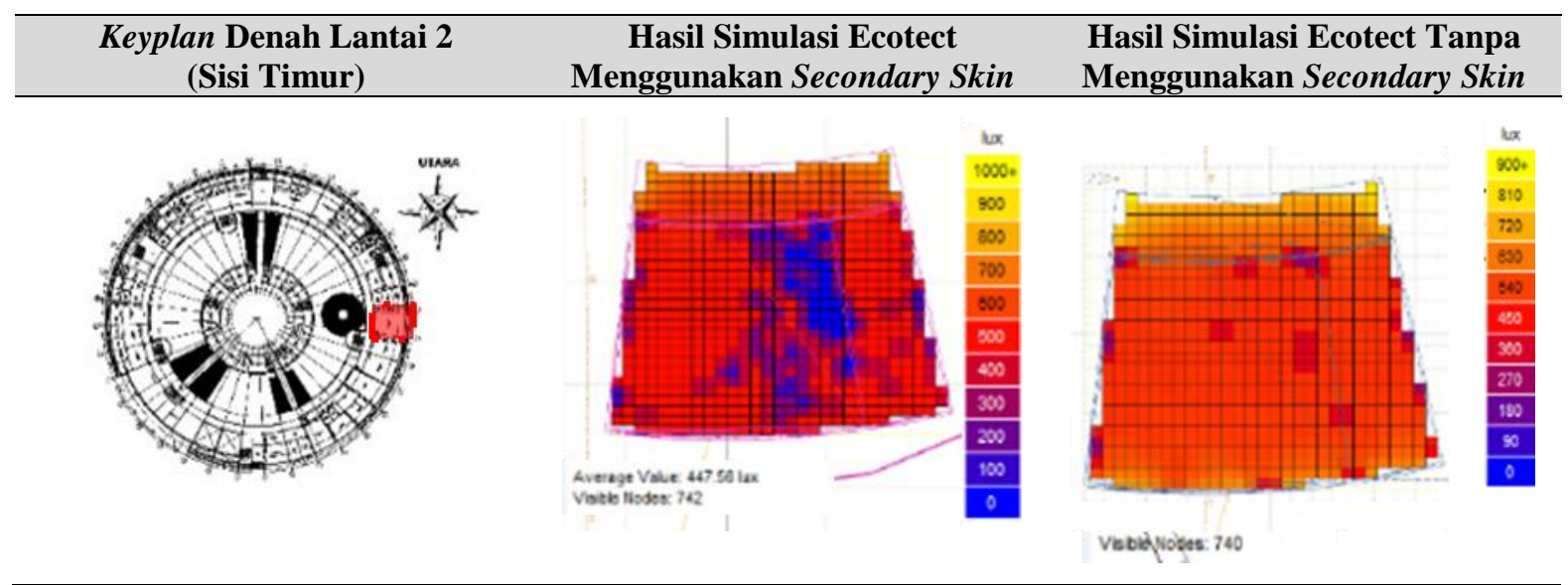

Sumber : Data PT. Architeam (2016) dan hasil analisis software Ecotect

\subsubsection{Ruang Hukum dan Tata Laksana (Barat)}

Simulasi pengukuran pada Ruang Hukum dan Tata Laksana yang menggunakan secondary skin pada jam 10.11 memperoleh kuat penerangan berkisar 430.69 lux, dan tanpa secondary skin pada jam yang sama memperoleh kuat penerangan berkisar 489.22 lux. Kuat penerangan pada Ruang Hukum dan Tata Laksana rata-ratanya tidak kurang dari 350 lux. Bukaan yang tidak menggunakan secondary skin mendapatkan intensitas cahaya yang lebih terang. Hasil simulasi kuat penerangan alami berupa spektrum warna, menggunakan software Ecotect dapat dilihat pada Tabel 9. 
Tabel 9. Perbandingan Kuat Penerangan Alami antara Menggunakan Secondary Skin dan Tanpa Menggunakan Secondary Skin, pada Ruang Hukum dan Tata Laksana

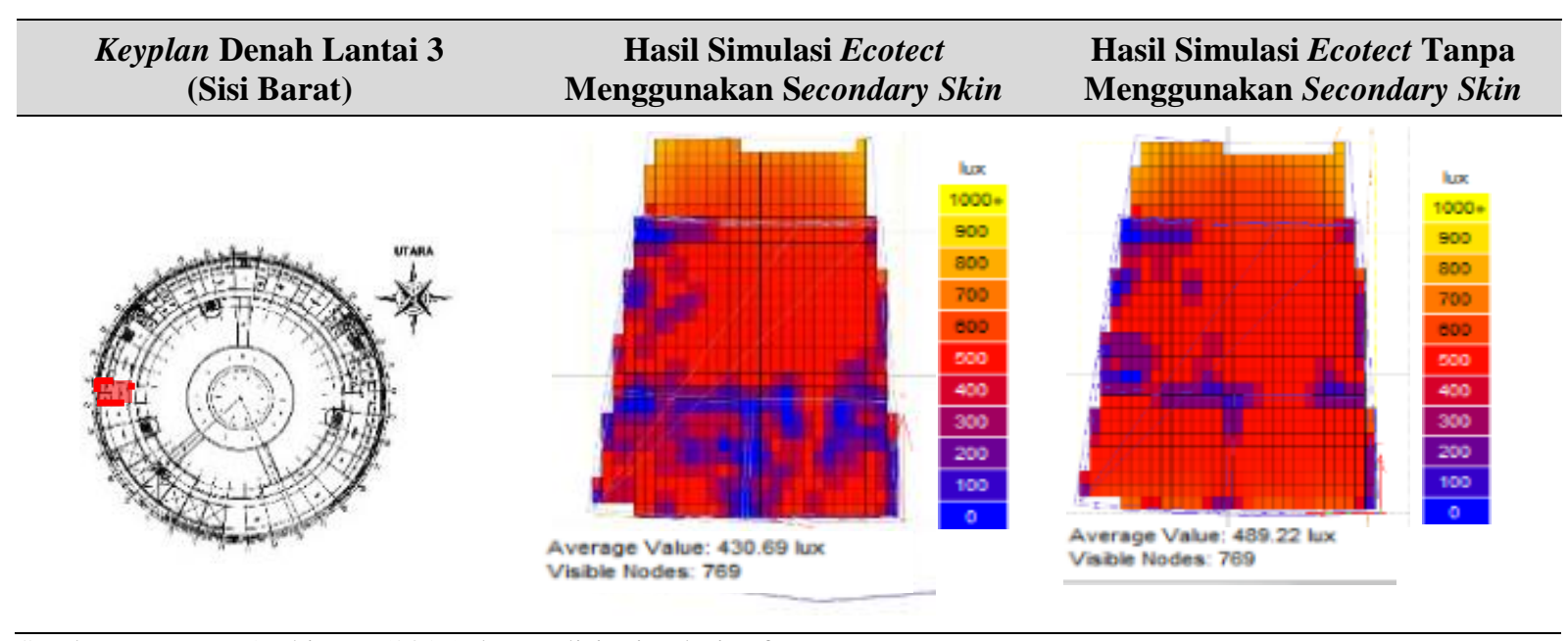

Sumber: Data PT. Architeam (2016) dan analisis simulasi software Ecotect

\subsubsection{Ruang Kepegawaian (Utara)}

Ruang Kepegawaian yang menggunakan secondary skin pada jam 09.09 memperoleh kuat penerangan berkisar 472.66 lux, dan tanpa secondary skin pada jam yang sama memperoleh kuat penerangan berkisar 492.26 lux. Dengan demikian kuat penerangan pada Ruang Kepegawaian rata-ratanya tidak kurang dari 350 lux. Bukaan yang tidak menggunakan secondary skin mendapatkan intensitas cahaya yang lebih terang. Hasil simulasi kuat penerangan alami berupa spektrum warna, menggunakan software Ecotect dapat dilihat pada Tabel 10.

Tabel 10. Perbandingan Kuat Penerangan Alami antara Menggunakan Secondary Skin dan Tanpa Menggunakan Secondary Skin, pada Ruang Kepegawaian

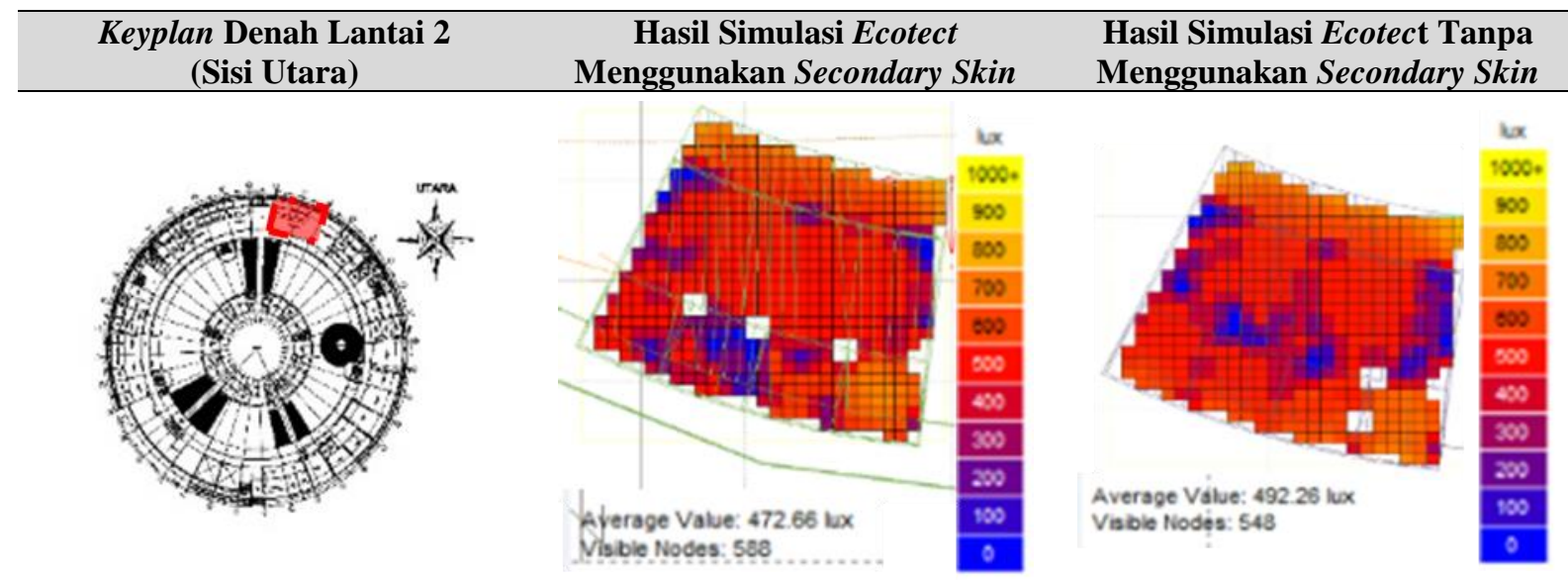

Sumber: Data PT. Architeam (2016) dan analisis simulasi software Ecotect

\subsubsection{Ruang VVIP (Selatan)}

Simulasi pencahayaan alami pada Ruang VVIP tanpa secondary skin pada jam 09.40 memperoleh kuat penerangan berkisar 527.69 lux. Kuat pencahayaan Ruang VVIP tanpa secondary skin sebesar 527.69 lux, jauh melampaui standar minimum SNI yaitu 350 lux, sehingga menimbulkan silau. Hasil simulasi kuat penerangan alami berupa spektrum warna, menggunakan software Ecotect dapat dilihat pada Tabel 11. 
Tabel 11. Kuat Penerangan Alami Tanpa Menggunakan Secondary Skin pada Ruang VVIP

\begin{tabular}{|c|c|c|}
\hline $\begin{array}{c}\text { Keyplan Denah Lantai 2 } \\
\text { (Sisi Selatan) }\end{array}$ & $\begin{array}{c}\text { Hasil Simulasi Ecotect Tanpa Menggunakan } \\
\text { Secondary Skin }\end{array}$ \\
\hline & & \\
\hline
\end{tabular}

Sumber: Data PT. Architeam (2016) dan analisis simulasi software Ecotect

\subsection{Tanggapan Persepsi Pengguna terhadap Kualitas Pencahayaan Alami Ruang Kerja}

Tanggapan persepsi pengguna terhadap pencahayaan alami pada ruang kerja Gedung Rektorat Unpad terhadap responden memberikan gambaran sebagai berikut :

1. Pada lantai dua setelah dilakukan pengamatan lapangan dan respon pengguna disimpulkan kondisi ruang yang cukup nyaman.

2. Pada lantai tiga setelah dilakukan pengamatan lapangan dan respon pengguna disimpulkan kondisi ruang yang cukup nyaman.

3. Pada lantai empat setelah dilakukan pengamatan lapangan dan respon pengguna disimpulkan kondisi ruang yang nyaman.

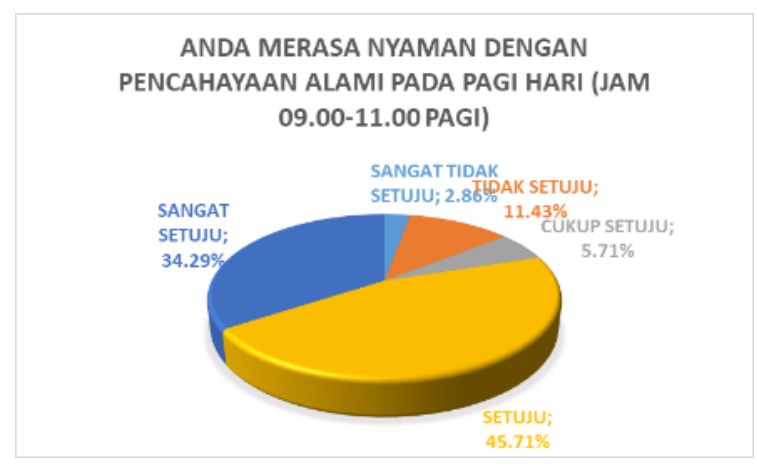

ANDA MERASA MEMERLUKAN PENCAHAYAAN BUATAN (LAMPU) PADA PAGI HARI

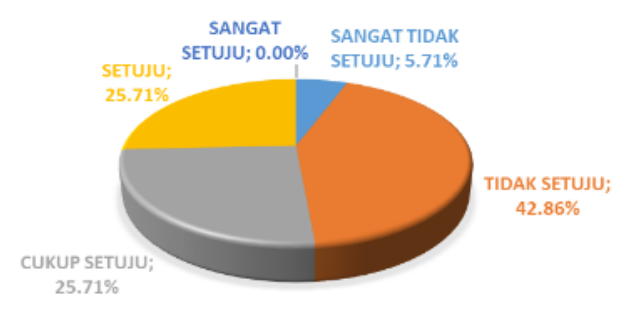

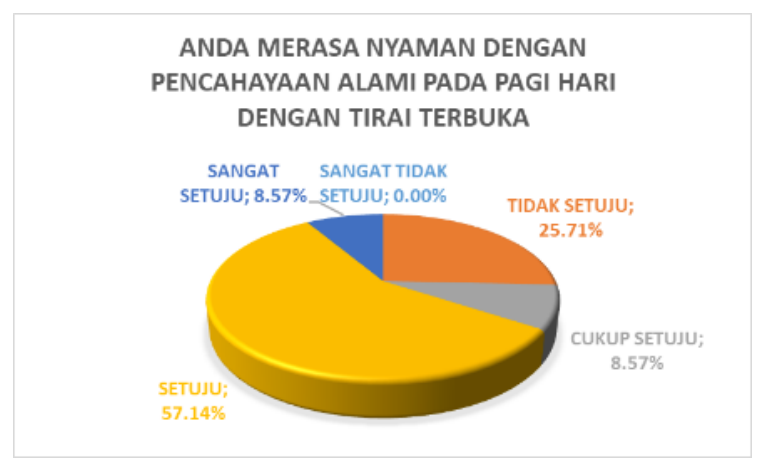

ANDA MERASA BEKERJA DENGAN NYAMAN APABILA LAMPU DIMATIKAN DAN TIRAI DIBUKA PADA PAGI HARI

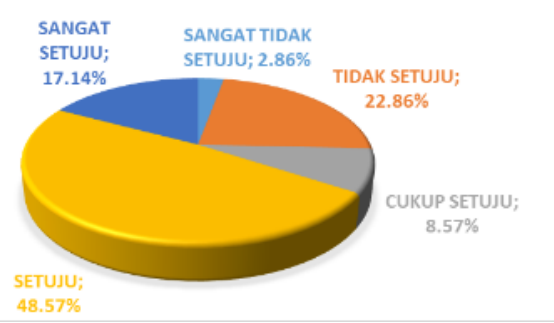



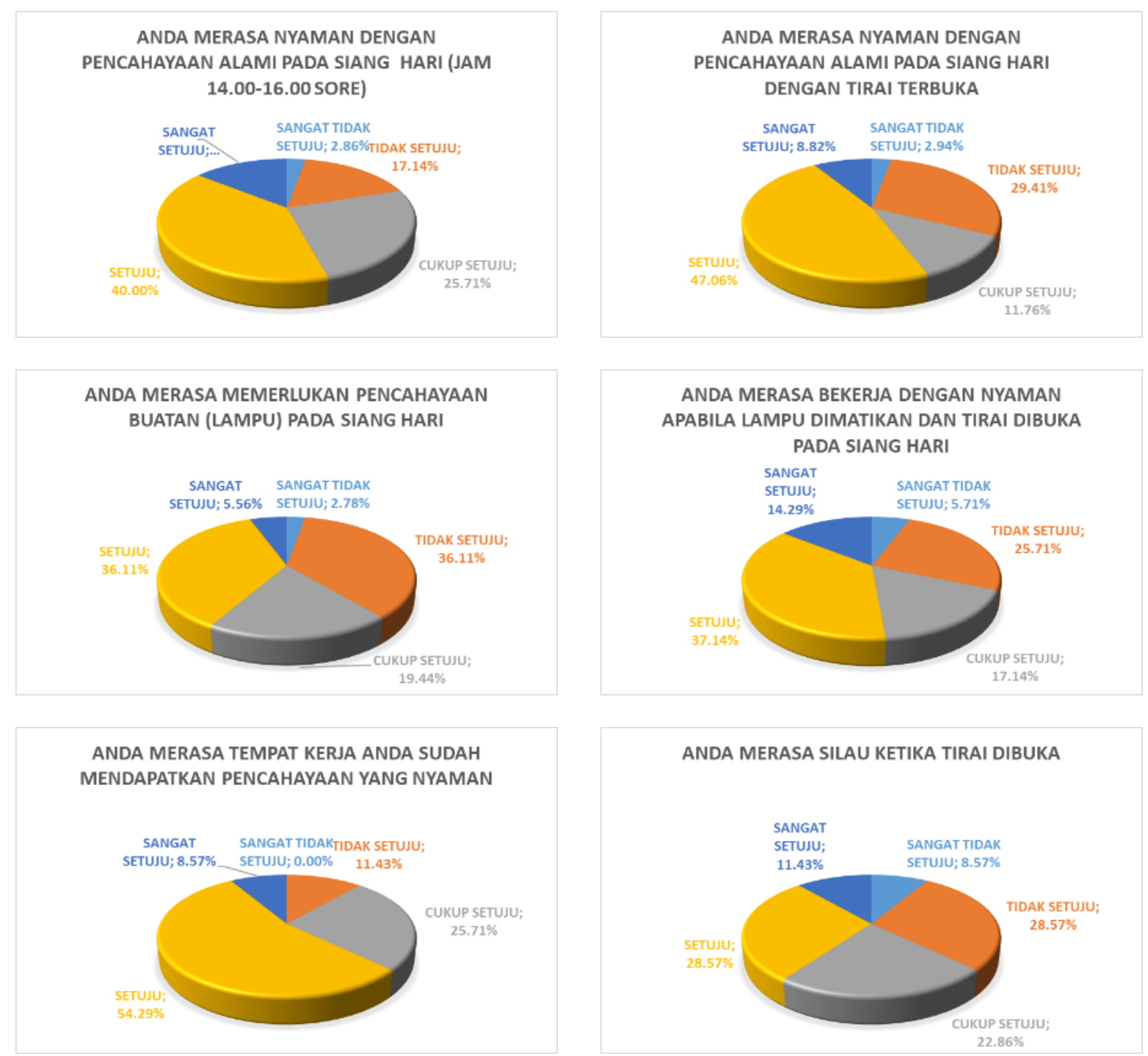

\section{Grafik 1. Hasil Tangapan Persepsi Pengguna terhadap Kenyamanan Pencahayaan Alami Sumber : Hasil Analisis}

\section{SIMPULAN}

Berdasarkan analisis dengan metode pengukuran menggunakan Luxmeter disimpulkan bahwa ruang menghadap secondary skin kuat penerangannya lebih tinggi dibandingkan yang menghadap koridor (tanpa secondary skin), tetapi sangat dipengaruhi oleh keadaan cuaca antara pagi hari dan sore hari yang berbeda, layout furnitur yang menghalangi bukaan, dan tirai bukaan yang permanen.

Metode pengukuran dengan simulasi software Ecotect pada model bangunan yang tidak menggunakan secondary skin mendapatkan hasil intensitas cahaya yang lebih baik dibandingkan dengan yang menggunakan secondary skin. Kuat penerangan dengan cahaya alami pada model bangunan yang menggunakan secondary skin rata-ratanya telah memenuhi standar tidak kurang dari 350 lux. Kuat penerangan alami yang menghadap Timur pada pagi hari dan yang menghadap Barat pada sore hari menghasilkan cahaya berlebih menimbulkan silau atau glare

Penggunaan secondary skin pada bangunan Rektorat Unpad dapat mempengaruhi kualitas pencahayaan alami, dimana cahaya yang menyilaukan (glare) dapat disaring oleh secondary skin tersebut, sehingga 
menghasilkan kualitas cahaya yang lebih baik. Sehingga penerapan secondary skin pada fasad dalam memberikan perlindungan faktor iklim eksternal terhadap bangunan, harus memperhatikan dampak terhadap penerangan alami yang akan terjadi pada ruang dalam bangunan.

\section{UCAPAN TERIMA KASIH}

Ucapan terima kasih kami sampaikan kepada semua pihak yang telah membantu memperlancar dalam penelitian ini hingga terselesaikannya laporan ini, di antaranya:

1. PT. Architeam, selaku konsultan yang memberi data gedung Rektorat Unpad berupa lembar kerja dll.

2. Bpk. Eli, selaku staf unit sarana prasarana Rektorat Unpad yang telah mengizinkan kami untuk melakukan pengukuran.

\section{DAFTAR PUSTAKA}

[1] N. L. Latifah, Fisika Bangunan 1, Penghawaan Alami \& Penerangan Alami, Pengendalian Termal (Solar Chart \& SPSM), 1st ed. Jakarta: Griya Kreasi, 2015.

[2] P. Boyce, "Lighting Quality for All," CISBE SLL Int. Light. Conf. - Dublin 2013. Sess. 3, pp. $1-5,2013$.

[3] K. Ulrich, T. Klein, M. Bilow, and T. Auer, Façades, Principles of Construction, vol. 53. 2007.

[4] A. Sandak, J. Sandak, M. Brzezicki, and A. Kutnar, Portfolio of bio-based façade materials. 2019.

[5] M. L. Yu, Skins, envelopes, and enclosures: Concepts for designing building exteriors. 2013.

[6] H. Poirazis, Double-skin façades - A literature review, vol. 49, no. 10. 2007.

[7] R. M. B. Jati, J. Thojib, and C. B. Amiuza, "Secondary Skin Motif Batik Jawa Timur Pada Hotel Di Surabaya," J. Mhs. Jur. Arsit., vol. 3, no. 1, pp. 1-14, 2015.

[8] Soegijanto, Bangunan Di Indonesia Dengan Iklim Tropis Lembab Ditinjau dari Aspek Fisika Bangunan. Jakarta: Direktorat Pendidikan Tinggi, Departemen Pendidikan dan Kebudayaan, 1999.

[9] N. L. Latifah, Fisika Bangunan 2, Kenyamanan Visual: Pencahayaan Alami dan Buatan, Kenyamanan Audial: Akustik dan Auditorium, 1st ed. Jakarta: Griya Kreasi, 2015.

[10] Badan Standardisasi Nasional, SNI 03-2396-2001 Tata Cara Perancangan Sistem Pencahayaan Alami pada Bangunan Gedung. Jakarta: Badan Standardisasi Nasional, 2001.

[11] Badan Standardisasi Nasional, SNI 03-6197-2000 Konservasi Energi pada Sistem Pencahayaan. Jakarta: Badan Standardisasi Nasional, 2000.

[12] D. L. DiLaura, K. W. Houser, R. G. Mistrick, and G. R. Steffy, The Lighting Handbook. 2011.

[13] J. Thojib and M. S. Adhitama, "Kenyamanan Visual Melalui Pencahayaan Alami Pada Kantor (Studi Kasus Gedung Dekanat Fakultas Teknik Universitas Brawijaya Malang)," Rev. Urban. Archit. Stud., vol. 11, no. 2, pp. 10-15, 2013, doi: 10.21776/ub.ruas.2013.011.02.2. 